\title{
Aithihyamala: Translating Text in Context
}

VRINDA VARMA

\section{Abstract}

Aithihyamala (1909) is a compilation of oral legends and folktales in Malayalam by Kottarathil Shankunni. A hundred years since its first publication, and many translations hence, re-translating it into English to suit the contemporary reader comes with its own share of challenges. Overcoming the barrier of archaic language was one thing as was the translation of cultural contexts and culture itself. But more demanding was the employment of a contemporary politically correct lens to the stories themselves, and exercising it in translation in such a manner that while the translation and the translator do remain invisible, the text is suitably modified in places so that blatant prejudices and partisanship inherent in the text do not overshadow the stories themselves. The paper discusses how the translator employed either domestication or foreignization and sometimes a combination of both in order to make sense of the canonical Malayalam text in English, and the rationale for employing each approach so as to make the text relevant and meaningful to the contemporary reader.

Keywords: Folklore, Canon, Culture, Language, Domestication, Foreignization.

\section{Introduction}

The transmission and dissemination of what we understand as folk, has always depended on translation from the oral to the literary. As much as folklore is a necessary agent of culture, its translation is also equally necessary for culture formation, which as Berman (1992: 105) says, inducts readers into the "the experience of the alterity of the world." For this experience of alterity perhaps, more than anything else, the 
Aithihyamala (1909) ${ }^{1}$ by Kottarathil Shankunni, first published more than a hundred years ago, still enjoys its cult place as canon even today and has had its share of translations. T. C. Narayanan has translated forty-eight stories from the original in his work Lore \& Legends of Kerala (2009), Leela James (2015) has translated fifty stories in three volumes while Sreekumari Ramachandran (2015) has translated the text in entirety. Venuti (2004: 25-38) maintains that while the first translation of a source text places it in such a manner so as to create awareness about its existence in the target language, recurring translations or retranslations serve to assimilate the work into the target language and thus target culture, thereby 'creating value' in the target culture. What retranslations primarily do, therefore, is to reinforce the value of the source text in the target culture while simultaneously extending the scope of the retranslation to move beyond the borders and the confines of mere language and syntax, and concern itself more with the values and institutions of the culture being translated.

Translating such a text that has already been valued in the target language comes with its share of concerns. While the translation shouldn't naturally assume that it seeks to do a better job, it should however try to address some issues in the source text as well the translated texts that precede it so that it lends itself to problematisation through translation. This paper is a result of the researcher's translation as well as the subsequent publication of seventy-five stories from the Aithihyamala (1909) as Lore, Legends, and Folktales from Kerala (2020) and it discusses how in her role as a translator, the researcher had to act as a mediator for not just the language, but the culture represented as well. While this is of

${ }^{1}$ While author refers to the first edition of Aithihyamala (1909) for general referencing, when it comes to specific references, the page numbers correspond to the latest edition of the work citied in line as Aithihyamala (2018). 
course what is expected from all translations where the translator seeks invisibility, the translator has also had to revalue her politics of dissidence (Venuti 1995: 148) through the translation itself. The paper seeks to acknowledge, how through the process of foreignization, domestication, and dissidence, certain inherent problems in the text like the treatment of gender, religion, and caste and the translations themselves like the seeming untranslatability of certain terms, myths, and practices in addition to the fundamental problems within translating from an indigenous language to a dominant language informed the translation of Aithihyamala (1909).

\section{Caste, Gender and the Problem of Language}

While the Aithihyamala (1909) is a collection of stories, it is also a collection of select stories, written from a very specific standpoint. The protagonists (other than gods and goddesses) of most stories are all mainly men, mostly from the Kerala Hindu upper caste, rarely common people, even rarely, women, which is telling on the caste and gender of the author, himself a Hindu male of the privileged upper caste. The protagonists of the stories are mostly rulers, or ministers in the royal court; Brahmins exemplars in medicine, sorcery, astrology, and other men of considerable historical or mythological repute. There are also many stories of elephants - an animal that is culturally significant to Kerala and its many temple festivals. One cannot however disregard the manner in which the stories revere the elite upper-caste male, while consciously relegate the female as well as the lower-caste male.

Research into patterns of discourse and narratives have proved beyond question, how language helps to privilege dominant groups in the society by aiding dominant ideological positions, thereby maintaining social consensus as well as consciousness regarding the dominant as well as peripheral roles of people in 
the society (Eagleton 1978; Thompson 1987; Simpson 1993). For a translator thus, the decision to translate certain prejudices inherent in the source text depended on the awareness of her role as an intercultural mediator and of the fact that translations serve to reinforce and perpetuate dominant and stereotypical elements of the source culture, hindering intercultural understanding and comprehension. For instance, in the chapter Shaktan Thampuran (Shankunni 2018: 299-332), there are many occurrences in the original text where Muslims are treated with disdain as well as contempt. In one instance, the eponymous protagonist, Shaktan Thampuran, a ruler of the erstwhile Kingdom of Kochi carries out the killing of over five hundred Muslim men in order to snuff out one petty highway robber. Shankunni speaks of the incident very subjectively, almost reverentially. To the contemporary sensibility, however, this is extremely problematic and hence, all care had to be taken while translating the incident, stripping the original text of the veneration Shankunni author lavishes on the ruler, so as not to offend sensibilities. But since it is of course a piece of history, the incident had to be included, albeit in objective terms, leaving it up to the readers to judge it for its merit alone.

When it came to Shankunni's pattern of using proper names for his characters, the problem of translation lay in also conveying a culture that attaches importance to the caste of the character in question. It was common (and it is sadly, prevalent still) for people in Kerala to address each other by caste names (for both upper and lower castes) or house names (mostly for people of the upper castes) rather than given names. D'Souza (1955: 28-44) has recorded how even when a person has many names (given name, father's name, family name, and caste name) that together constitute his full name, not all names are equally important: substantive or prepotent names are the names of the families and the name that identifies the caste of the person. In Shanunni's Aithihyamala too, this practice is 
common. For instance, a Namboothiri of the illam of Poomulli would be referred to as Poomulli by other Namboothiris in the oral dialogues, while he would be referred to as Poomulli Namboothiri or simply Namboothiri in the narrative text. A person belonging to a lower caste would merely be referred to by their caste names like Menon or Thandan or Nair, rarely by their family names, and almost never by their given names unless they were the titular characters in a story, like in the case of Ramapurathu Warrier, where, Ramapuram is the name of a place and not the person himself (Shankunni 2018: 281282) or were otherwise relevant to the story as an important character rather than a character in the background. Shankunni is unjustifiably judicious when it comes to the names of his women characters, where, even the titular character in the stories Arakkal Beebi (Shankunni 2018: 916-920), and a significant character in the story Pathayikkara Namboorimaar (Shankunni 2018: 163-166), are not given proper names, but are merely referred to as "the beebi" (meaning 'lady' in Muslim parlance) or "the antharajanam" (literally "the woman inside') to refer to married Namboothiri women. The number of stories that carry a woman protagonist is comparatively quite small in number as compared to their male counterparts and this is also reflective of the gender of the number of characters in the entire volume. In most cases, the women characters in the periphery of the stories are simply Namboothiri, Nair, Kaniyar, Shudra stree (woman) among others, and not distinguished otherwise by either family names or proper names.

Sreekumari Ramachandran in her translation of the Aithihyamala, The Great Legends of Kerala (2015) has dealt with the problem of cultural representation as well as the semantics of language by providing fictional names for the characters who appear without their given names. Appukuttan Nair (Ramachandran: 176), Appan Thampuran (265), Radha 
(368), Damodaran Namboothiri (519) are all fictitious names coined by Ramachandran (2015) that are peppered throughout her translation. This however only serves to reaffirm the subversion performed by Shankunni in the original text. The characters, especially the ones in the periphery of the stories, marginalised by the author by stripping them of their given names and limiting them to just caste-based identifiers, are now provided fictional names, thus deleting their original identity altogether. While this translator was aware that she was perpetuating the stereotype of the society where caste, as well as male gender, was privileged above anything else, it was also deemed necessary to retain the names, or the lack of it thereof, in order to remain faithful to the source text as well as the target reader of not just the stories themselves, but also the culture embedded in them, together with the real people who are referenced to in the stories, albeit on an incidental level.

Linguistically, this omission of first names created a significant problem for the researcher/translator. In the story Mangalappilli Moothathum Punnayil Panikkarum (Shankunni 2018: 110-114) for instance, there is a reference to a man called Potti. Pottis, according to Menon (2007: 85) are Brahmins of Kerala with Tulu (Karnataka) origins. The protagonist in the story bears no surname and is referred to by just his surname of Potti. Additionally, many other people present themselves in the story, all bearing simply the surname of Potti. How to differentiate the different Pottis then? Should an article be used before the protagonist, referring to him as 'the Potti', while others remain "that Potti" or "another Potti", or should fictitious first names be given? In the end, it was decided to use the definite article before the surname. Though the use of a definite article before a name might seem odd to a native speaker of the language, this has had to be done in many instances in the text, simply because in Kerala as with many parts of India, a surname is not merely a name; it is a sum total 
of a cultural significance: caste, gender, religion, occupation, origins and social position among many others. Hence, throughout the stories, the reader will come across "a Nair", "an Ezhuthachan", "the Embran", "the Mooss", "an Ezhava" and so on.

Thus, in spite of the problems of cultural representation as well as linguistic difficulties, the retranslation remained true to the source text, while being acutely aware of perpetuating the social consensus of the importance being given to caste in the Hindu society.

\section{Foreignization and Domestication: Dealing with the "Untranslatable" Terms}

Although Aithihyamala (1909) can be read and enjoyed by both children and adults, a contemporary reader with at least a cursory understanding of the milieu and contexts in the stories would tend to appreciate its essence better. Having said so, however, many terms, cultural references, and usages in the source text are in themselves non-accessible to contemporary readers, even in the source language. Hence, translating it into a global language retaining the flavour and nuance of the original was especially challenging. In the exercise of translation thus, achieving 'interlingual equivalence' (Munday 2014: 74) was given precedence over equivalence of meaning in many instances, especially with respect to culture-specific terms and connotative meaning, where many key features are implicit, hence posing a challenge in translating. To achieve this interlingual equivalence, the translator has had to resort to both domestication and foreignisation to achieve satisfactory results.

It can be argued that the role of a translator is to bridge the gap between the source language and target language and the source culture and foreign culture and that this can be achieved by the domestication of the source text in the target language. 
While retranslating the Aithihyamala (1909), however, it seemed imperative to regard the source text as a telling document of a culture that in spite of its inherent bias and prejudices was an important text in the culture and ethos of Kerala. Hence, bending over backward to domesticate the text in the target language was understood by the translator as an exercise in stripping the text of much of its mirroring of society and social life a few centuries ago, albeit from an ableist perspective. Hence, while the syntax of the language was kept simple and accessible, many terms had to be retained in their original form, preferring foreignization as a technique rather than domestication, with the foreign words being appropriately glossed or explained in footnotes. Another rationale behind this approach was the assumption that at least some readers of the retranslation of Aithihyamala (1909) would be persons familiar with the culture and the Malayalam language as it is, previously familiar or unfamiliar with the source text, in addition to an abecedarian, completely new to the culture and language of the source text. Thus, while the former type of reader would appreciate the familiarity of the words and their cultural implication, the latter type of reader might be expected to welcome the opportunity to peek into the source culture. This foreignization is standard practice by translators of the native and it signals the "linguistic and cultural difference of the foreign text and performs a work of cultural restoration, admitting the ethnodeviant and potentially revising domestic literary canons" (Venuti 1995: 148) and was necessary to thus simultaneously domesticate and as well as foreignize certain terms in the main text.

While domesticating many culture-specific terms, the translator chose a near equivalent term in the target language, which conveyed the essence of the word, if not in entirety, to the nearest possible in any which case. For instance, thidappalli refers to the kitchen in a temple, where food for the 
gods is prepared. Instead of glossing the word or foreignizing it, thidappalli was merely translated as temple-kitchen. In certain cases, coalescent domestication was adopted to privilege readability. For example, nivedyam and vazhipaadu are both translated as "offering" in the target language. But while nivedyam is food that is first offered to the personification of the deity and then distributed to the devotees, vazhipaadu is a set of rituals and prayers that a devotee entrusts a priest to perform to the deity on their behalf, most usually for some sort of wish fulfillment. The devotees are then given back flowers, sandal paste, turmeric, or kumkumam (slaked lime mixed with turmeric) used for the vazhipadu and even the edible panchamritham, thrimadhuram or payasam as a sort of acknowledgement of the vazhipadu performed. Often, both these different words have had to be curtailed to the bland English equivalent: 'offering'. This does create a loss of subtlety, but often, readability and the reader have had to be privileged more than the text itself.

Words like bhajana, paavumundu, veeralippattu, Chathan, illam, yakshi, velichappadu and so on while can be translated using a set of words in the target language, if not a single word alone, has nevertheless been retained as it is in the main text and provided with a note or gloss to explain further. This approach has been guided by Venuti's (1995: 15) view that an overt domestication is a dangerous approach that "provides the target-language reader with the narcissistic experience of recognizing their own culture in a cultural other". Venuti further argues that such domestication makes the target language reader "aggressively monolingual and unreceptive to the foreign".

In this context, the terms Chathan, yakshi and velichappadu deserve special mentions. Chathan is sometimes seen translated as a devil in many translations of Malayalam texts in 
English. Chathan seva or Chathan worship is thus correspondingly translated as devil worship. However, the imagery brought forward by the use of the terms Chathan and Chathan seva cannot be equated with devil worship. While the devil is understood as the objectification of a negative force, Chathan is regarded more as a kind of pest, controlled by people who practice black magic, than as evil in itself. Those who believe in Chathan believe that
"he is the son of (Lord) Shiva and (Goddess) Parvati while they had assumed their tribal forms. Another belief is that Chathan is the son of Shiva and the female version of Lord Vishnu (Vishnumaya). According to this belief, people believe that Chathan is another name of Shasthavu or Ayyappan. Chathan is not considered among other Hindu gods, but is often seen as an amalgam of the destructive force of Lord Shiva and the calmness of Lord Vishnu. The form of worship of Chathan is believed to invoke many tantric as well as black magic practices" (Varma 2020: 411).

Chathan is believed to be controlled by tantrics who specialise in that particular mode of worship. Avanangatt Panikkarum Chathanmaarum (Shankunni 2018: 598-608) describes the mode of Chathan worship to some extent, but never really explains who/what the Chathan is. It was thus imperative that the term be used as it is in the main text, without resorting to domestication, but glossed and explained in references nevertheless so as make its meaning more accessible to the target reader. Another problem faced by the translator when it comes to Chathan is Shankunni's use of both the plural Chathanmar as well as the singular Chathan interchangeably to speak of the spirits. While in certain cases the use of the plural form was justified, it remained ambiguous in many other 
instances. In the end, the translator followed Shankunni's lead and chose to be faithful to his use of the noun-number.

Yakshi is an important character in Aithihyamala (1909), appearing in many stories, in many forms. In translating Vadakkan Aithihyamala (1970) into its English Lore and Legends of North Malabar (2016), Ashvin Kumar has described a yakshi as being closer to elves in Germanic Mythology (2016: 551) while also claiming aptly that the term has no English equivalent. Sindhu Jose in her doctoral dissertation, Representation as Translation a Reading of the Adaptations of the Yakshi Myth in Malayalam, says, "The myth of Yakshi...exists in the collective imagination of Kerala as a perennial symbol of haunting and seduction" (2018: 3). Yakshi in Aithihyamala (1909) appears as a loving wife (albeit invisible) in the stories Vayaskkara Chaturvedi Bhattathiriyum Yakshiyum (Shankunni 2018: 279-281) and Venmani Namboothirippadanmar (Shankunni 2018: 125-131); as a man hunting seductress who is later tamed by exorcism and worshipped as goddesses in Kadamattathu Kathanar (Shankunni 2018: 462-477) and Kumaramangalath Namboothiri (Shankunni 2018: 949-954) and as the divine in Panachikkad Saraswathi (Shankunni 2018: 747-751) in addition to minor mentions in many other stories. Even readers who are not familiar with the many forms of the yakshi in Aithihyamala might however be familiar with the yakshi motif in the space of Malayalam film and television where she is portrayed as the "monstrous feminine - the abject un-dead" (Jose 4). It was thus imperative to retain the Malayalam word for the mysterious being, hoping that each story would unfold on its own the many associations the word brought along with it.

Another term that has been retained as it is in the source language, in spite of having an English equivalent is 
Velichappadu. The target language translation of this term is oracle $^{2}$. However, the image of a man dressed in red, with his hair grown out, wearing a thick belt of bells and holding a curved sword in his hand, sometimes with blood gushing from a wound on the forehead perpetuated by repeated beating of the sword in a frenzy is lost when velichappadu is translated as "oracle", which in the western mythical context, is for starters almost always female, while in the context of Kerala, almost always male unless in other specific circumstances like the Bharani festival at Kodungallur (Gentes 1992). Invoking this image of the velichappad was considered paramount to enable a translation of culture from the source language to the target language and was hence retained as it was.

\section{Translating in Context}

The problem of domestication or foreignization was also relevant when it came to the translation of certain rituals, practices, and customs, neither in practice now, neither familiar to contemporary readers. In the story Kulappurath Bheeman (Shankunni 2018: 445-451) for instance, there is a part where Bheeman, the eponymous character draws water out of a well with his left hand. The original Malayalam text can be simply translated as "Bheeman held the rope in his left hand and went to the well." Now, the use of the left hand is used to exemplify the brute strength of the character, but there is a smaller instance that requires some explanation. Bheeman was having his food when he was called to draw water from the well. Hence, his right hand, with which he was eating was 'polluted' and could not be used to draw water from the well. This concept of pollution or echil will not be understood by a person who has no prior understanding of the Hindu culture, not just in Kerala, but the rest of India too. Echil, (uchishta in

\footnotetext{
${ }^{2}$ M J Gentes (1992: 295-322) has used the term "illuminator" to refer to the oracle.
} 
Sanskrit) refers not just to the remains or leftovers of the food eaten by a person, but it also refers to the utensils like plates and tumblers used by the person consuming food, as well as hands and mouth of the person (Patrick 1999: 354-355). Thus, in Malayalam, echil paathram (polluted vessel), echil kayy (polluted hand) and echil (polluted food) are terms that are quite common and still in practice in many homes, but the ancient/Vedic concept, as well as practice, is quickly making its way out in modern times. While many terms can be glossed or explained as footnotes, instances such as these cannot be over-explained in the text, as it is bound to hamper readability. But, while a reader of the Malayalam text will read the instance of the left hand in its full context, a reader of the same in English would be devoid of context. While translating the instance, therefore, preference had to be given to a demonstration of the strength of the character rather than the concept of echil as would probably have been the intention of Shankunni too.

Similarly, in the story Pathayikkara Namboorimaar (Shankunni 2018: 163-166) there is an instance where the Namboothiri protagonist of the story keeps a grinding stone on the rafters and his wife takes it down, uses it for grinding rice, and keeps it back again. Just summarising this instance here has looted the significance of the event. The grinding stone referred to here is aattukallu in Malayalam. It is a very heavy circular slab of granite with a depression in the centre where pulses and grains are ground with an oblong granite stone that is also equally heavy. A person familiar with Malayalam will associate so much with the term aattukallu than with its near equivalent in English - grinding stone. Though the verbatim translation cannot be faulted, it lacks the flavour that the Malayalam original would provide. What is lost in such a translation is both the signified and the signifier, since such traditional tools are now long gone from the Kerala kitchen, 
replaced by modern cooking equipment like the grinder. Hence, both aattukallu, as well as griding stone, were used in the text, so that to readers who are familiar with the tool, it would help add a more nuanced understanding, while for others, it is a brush with the past, hitherto unfamiliar to them.

Some other practices like the manner in which a lower caste would refer to himself as adiyan when in conversation with a higher caste, the excessively reverential language used in the source text while referring to the king, and various reverential terms associated with monarchy like the prefixing of palli (royal) in front of urakkam (sleep), ara (bedroom/bed chamber), thevaaram (prayer) were dispensed with in favour of common; everyday translation of the words since it was understood by the translator that such terms do not hold value in a largely democratic society of today.

\section{The Move from Oral Tradition to Classical}

It has already been mentioned that the first translation of Aithihyamala (1909) was from oral to literary. As a result of which the stories themselves moved from folk tradition to classical tradition, from Little Tradition to Great Tradition (Thomas \& Arulmozhi 2020: 55). This transition from folklore to classical encompasses many factors, an important one being its acceptance and appropriation of hegemonic language structures. Shankunni's Aithihyamala (1909) has many verses and slokas interspersed with the main text, both in Malayalam as well as Sanskrit. Stories like Kalidasna (838-856), Bhavabhuti (153-154) Swati Thirunal Maharaajavu Thirumanassukondu (409-417), and many more contain not just one, but many Sanskrit verses that serve to exemplify the poetic genius of the titular characters in the story. But while Shankunni offers a paraphrase for most of the verses in Kalidasan, he does not offer to do the same for many of the other Sanskrit verses and slokas in the text. Shankunni himself 
was well acquainted with Sanskrit and thus possibly quite familiar with these verses. To a casual reader, however, the meanings are beyond reach, and unless if one takes into account Shankunni's intention to display his scholarship in Sanskrit, they do not really contribute to the process of meaning-making and interpretation of the text for a reader. They do, however, play a role in shaping the text into the literary canon, a method followed by many scholars/authors during his time, not just in Malayalam but also in the many other languages of the Indian subcontinent. By using Sanskrit verses liberally, not only was Shankunni appropriating many folk tales into the upper caste narrative, and thus giving it literary validity, he was also attempting to give the tales 'structural relevance' (Srinivas, 2002: 222). This process of Sanskritization was, however, no longer necessary for the translation of an already canonised text. Hence, most of the verses that were included in the main text without any explanation were chiselled out or merely paraphrased (whenever possible) into the main text. T. C. Narayanan (2009), Sreekumari Ramachandran (2015), and Leela James (2015) have also refrained from translating the Sanskrit verses found in the source text, with Ramachandran mentioning explicitly that verses have been left out by the translator.

Certain Malayalam verses too remained untranslatable, owing to the ambiguity it carried along with it. For example, the story Azhvanchery Thamprakkalum Mangalath Shankaranum (177180) ends with a small alliterating verse in Malayalam that lists out ten items that begin with the sound 'pa', foregone by the Azhvanchery family for reasons explained in the story. Though each of these ten items can be literally translated to English, one item, in particular, eluded comprehension. The eighth item in the list is paithal meaning child. However, it escapes why a child should be among a list of items given up by the family. It definitely could not stand for progeny, but 
what then, and in what context? The verse was thus transliterated and retained in the text, without further explanation so as to lend to multiple interpretations, given that the original context is presently lost to us.

\section{Conclusion}

As with any translation such as this, the translator is perennially stuck with the option of staying true to the voice of the text and providing a fresh voice to a text that would be read by a completely different set of readers than the ones written for initially. For a text as culturally heavy as Aithihyamala (1909), a translator cannot simply get away with domesticating the text, it needs to find the right balance between sticking to the tone of the original, while laying aside the temptation to colonise it, given the many standpoints and references in the text that might grate on modern sensibilities. The politics of dissidence makes itself clear in the way in which the translator chose to domesticate certain terms while simultaneously choosing to foreignize certain others. From choosing to refrain from providing fictional names to characters, retaining culturally loaded terms like Yakshi and Chathan, omitting to privilege Sanskrit as had been done in the original to trying to tone down inherent prejudices within the source text, the translator has tried to maintain a contemporary political consciousness in the translation while simultaneously attempting to retain the cultural ethos of the source text. In the end, however, this translation of the Aithihyamala (1909) too, bids do what most re-translations have done, that is, affirm the self-evidence of the original, while also predicting the possibility of further and better translations in the future.

Note: Some of the ideas expressed in this paper were originally published in the Tranalator's Note that appeared in the English translation of Aithihyamala, published by DC Books, Kottayam, Kerala, India. 
Aithihyamala: Translating Text in Context

\section{References}

Berman, Antonie. 1992. The Experience of the Foreign: Culture and Translation in Romantic Germany. Albany: State University of NY Press.

D'sOUZA, VICTOR S. 1955. Sociological Significance of Systems of Names: With Special Reference to Kerala. Sociological Bulletin 4 (1). 28-44.

EAGLETON, TERRY. 1979. Ideology, Fiction, Narrative. Social Text 2. 62-80.

GENTES, M. J. 1992. Scandalizing the Goddess at Kodungallur. Asian Folklore Studies 51( 2). 295-322.

JAMES, LEELA. 2015. Aithihyamaala: The Garland of Legends, vol. 3. Delhi: Hachette India.

JOSE, SINDHU. 2016. Representation as Translation a Reading of the Adaptations of the Yakshi Myth in Malayalam. Hyderabad: The English and Foreign Languages University. (Doctoral Dissertation.)

KUMAR, ASHVIN. 2016. Lore \& Legends of North Malabar: Selections from the Vadakkan Aithihyamala. DC Books. (Translator's Note.)

Menon, Sreedhara A. 2007. A Survey of Kerala History. Kottayam: DC Books.

Munday, Jeremey. 2014. Text Analysis and Translation. In Bermann, Sandra \& Porter Catherine (eds.), A Companion to Translation Studies. West Sussex: Wiley Blackwell.

NARAYAN, T. C. 2009. Lore \& Legends of Kerala. New Delhi: OUP.

Nivea K Thomas \& ARUlmozhi S. 2020. From Little Tradition to Great Tradition: Canonising Aithihyamala. Translation Today 14(1). 51-63.

Olivelle, PATRICK. 1999. The Dharmasutras: The Law Codes of Ancient India. New York: Oxford University Press.

RAMACHANDRAN, SREEKUMARI. 2015. Aithihyamala: The Great Legends of Kerala. vol 2. Mathrubhumi Books. 
ShankUnNi, KotTarathil. 1909. Aitihyamala. vol. 1. Thrissur: Vellaykkal Narayana Menon.

SHANKUnNI, KotTARATHIL. 2018. Aithihyamala. 12th edn. Kottayam: DC Books.

Simpson, P. 1993. Language, Ideology and Point of View. London: Routledge.

SRINIVAS, M. N. 2002. Collected Essays. Oxford University Press.

THOMPSON, JOHN B. 1987. Language and Ideology: A Framework for Analysis. The Sociological Review 35(3). 516-536.

VARMA, VRINDA. 2020. Lore, Legends and Folktales of Kerala. Koyyatam: DC Books.

VENUTI, LAWRENCE. 1995/2008. The Translator's Invisibility: A History of Translation. New York: Routledge.

VENUTI, LAWRENCE. 2004. Retranslations: The Creation of Value. Bucknell Review 47(1). 25-38.

\section{Cite This Work:}

VARMA, VRINDA. 2021. Aithihyamala: Translating Text in Context. Translation Today, Vol. 15(1). 54-71.

DOI:10.46623/tt/2021.15.1.ar3 